\title{
Effect of insulin-transferrin-selenium (ITS) and L-ascorbic acid (AA) during in vitro maturation on in vitro bovine embryo development
}

\author{
A.L.S. Guimarães ${ }^{2}$, S.A. Pereira ${ }^{3}$, M. N. Diógenes ${ }^{2}$ and M.A.N. Dode Di,2, $^{1,4}$ \\ School of Agriculture and Veterinary Medicine, University of Brasilia, Brasília-DF, Brazil; Institute of Biology, University of \\ Brasília, Brasília-DF, Brazil; and Embrapa-Genetic Resources and Biotechnology, Brasília - DF, Brazil
}

Date submitted: 07.09.2015. Date revised: 24.06.2016. Date accepted: 09.07.2016

\section{Summary}

The aim of this study was to evaluate the effect of adding a combination of insulin, transferrin and selenium (ITS) and L-ascorbic acid (AA) during in vitro maturation (IVM) and in vitro culture (IVC) on in vitro embryo production. To verify the effect of the supplements, cleavage and blastocyst rates, embryo size and total cell number were performed. Embryonic development data, embryo size categorization and kinetics of maturation were analyzed by chi-squared test, while the total cell number was analyzed by a Kruskal-Wallis test $(P<0.05)$. When ITS was present during IVM, IVC or the entire culture, all treatments had a cleavage and blastocyst rates and embryo quality, similar to those of the control group $(P<0.05)$. Supplementation of IVM medium with ITS and AA for $12 \mathrm{~h}$ or $24 \mathrm{~h}$ showed that the last $12 \mathrm{~h}$ increased embryo production $(51.6 \% ; n=220)$ on D7 compared with the control $(39.5 \% ; n=213)$. However, no improvement was observed in blastocyst rate when less competent oocytes, obtained from 1-3 mm follicles, were exposed to ITS + AA for the last $12 \mathrm{~h}$ of IVM, with a blastocyst rate of $14.9 \%$ $(n=47)$ compared with $61.0 \%(n=141)$ in the control group. The results suggest that the addition of ITS alone did not affect embryo production; however, when combined with AA in the last $12 \mathrm{~h}$ of maturation, there was improvement in the quantity and quality of embryos produced. Furthermore, the use of ITS and AA during IVM did not improve the competence of oocytes obtained from small follicles.

Keywords: Antioxidants, Bovine, Embryo, Maturation, Oocyte

\section{Introduction}

Among the steps in in vitro embryo production (IVP), in vitro maturation (IVM) is one of the most critical, because the oocytes used are usually obtained from

\footnotetext{
${ }^{1}$ All correspondence to: Margot Alves Nunes Dode. Parque Estação Biológica, Final Av. W5/N, Prédio PBI, 70770-900, Brasília - DF, Brazil. Tel.: +55 61 34484659. Fax: +55 613340 3658. E-mail: margot.dode@embrapa.br

${ }^{2}$ School of Agriculture and Veterinary Medicine, University of Brasilia, Brasília - DF, Brazil.

${ }^{3}$ Institute of Biology, University of Brasília, Brasília - DF, Brazil.

${ }^{4}$ Embrapa-Genetic Resources and Biotechnology, Brasília DF, Brazil.
}

a heterogeneous population of follicles. Consequently, their competence for developing to the blastocyst stage and maintaining pregnancy will vary (Caixeta et al., 2009; Racedo et al., 2009).

One of the many aspects that may affect IVM is reactive oxygen species (ROS) generation, which leads to oxidative stress and alterations of the cell functions. When oocytes are handled, prepared and manipulated for IVM procedures, they are exposed to various potential ROS-inducing factors, including exposure to visible light, culture media composition, $\mathrm{pH}$, temperature and oxygen concentration - for a review see Agarwal et al.(2014). Thus, an alternative that may protect against oxidative stress during in vitro culture (IVC) would be antioxidant supplementation of the media (Chwa et al., 2006). 
An insulin-transferrin-selenium combination (ITS) is reported to provide better rates of nuclear and cytoplasmic maturation of porcine oocytes (Hu et al., 2011) and cattle IVP embryos (Dalvit et al., 2005). Recently, supplementation of IVP medium with ITS was shown to significantly improve the blastocyst rates and quality of bovine embryos when an individual-culture system was used (Wydooghe et al., 2014).

Insulin induces the uptake of glucose and amino acids and has mitogenic and anti-apoptotic activity, increasing cleavage and blastocyst rates in bovines (Augustin et al., 2003; Lee et al., 2005). Transferrin and selenium are trace elements that have antioxidant activity. The combination of these two elements in cell culture media causes a reduction in free radical production and lipid peroxidation (Kim et al., 2005); in addition, their presence greatly enhances the maturation of oocytes, decreasing polyspermy and increasing pronuclear formation (Tatemoto et al., 2004; Cerri et al., 2009).

L-Ascorbic acid (AA) has an important antioxidant role, and certain intracellular concentrations of this substance in the oocyte seem to be essential for cytoplasmic maturation. Although adding AA to the culture medium improves blastocyst production in mice (Tilly \& Tilly, 1995; Eppig et al., 2000), its addition to the maturation medium exerted no effect on developmental competence of bovine and porcine cumulus-oocyte complexes (COCs) (Blondin et al., 1997; Tatemoto et al., 2004; Dalvit et al., 2005; Córdova et al., 2010; Tao et al., 2010; Kere et al., 2013). Furthermore, when ITS and AA are added together during the maturation of oocytes obtained from pre-pubertal bovine (Córdova et al., 2010) and goat females (Hammami et al., 2013), an improvement in cytoplasmic maturation was observed, as evidenced by the embryo yield. Considering that those oocytes are typically less competent for development than those obtained from adult animals, these results indicate a beneficial effect of ITS and AA on oocyte competence.

Apart from the data presented by Córdova et al. (2010) and Hammami et al. (2013), there are few reports on the effect of ITS alone in cattle (George et al., 2008; Dalvit et al., 2005), and even fewer reports on its use in association with AA during different periods of culture. Nevertheless, these supplements represent an alternative strategy to improve environmental conditions for IVM and, thus, the results of IVP. Therefore, we tested the effect of ITS during IVM and IVC on the quantity and quality of IVP embryos. We hypothesized that antioxidant supplementation for different periods during IVM in oocytes with different competencies could improve oocyte potential and embryo development.

\section{Material and methods}

Unless otherwise indicated, the reagents and chemicals used in this research and for the preparation of the maturation, fertilization and IVC media were purchased from Sigma (St. Louis, MO, USA).

\section{Collection and classification of oocytes}

Ovaries from crossbred adult cows were collected at a local slaughterhouse and transported to the laboratory in saline solution $(0.9 \% \mathrm{NaCl})$ supplemented with antibiotics $(100 \mathrm{IU} / \mathrm{ml}$ penicillin $\mathrm{G}$ and $100 \mu \mathrm{g} / \mathrm{ml}$ streptomycin sulfate) at $37^{\circ} \mathrm{C}$. In the laboratory, follicles that were $3-8 \mathrm{~mm}$ in diameter were aspirated by vacuum pump. Only the COCs classified as grades 1 and 2 were used.

To obtain COCs with different degrees of competence, we used the previously described model (Caixeta et al., 2009). Briefly, 1-3 mm and 6$8 \mathrm{~mm}$ diameter follicles were dissected from the ovarian cortex using tweezers, scissors and a scalpel. Once dissected, the follicles were measured using a graduated ocular device (eyepiece micrometer OSM4 Olympus $^{\circledR}$, Tokyo, Japan). To release COCs, the follicles were ruptured, and only those oocytes with at least four layers of cumulus cells and a homogeneous cytoplasm were used for further work. The whole process was conducted in washing medium [TCM-199 with Hank's salts (Gibco ${ }^{\circledR}$ Invitrogen, Carlsbad, CA, USA) supplemented with 10\% fetal bovine serum (FBS; Gibco BRL, Burlington, ON, Canada) and $0.075 \mathrm{mg} / \mathrm{ml}$ of amikacin].

\section{Assessment of nuclear maturation}

For meiotic stage evaluation, oocytes were denuded and fixed for at least $48 \mathrm{~h}$ in a fixing solution consisting of 3:1 glacial acetic acid and ethanol. For evaluation, oocytes were placed on a slide, covered with a coverslip and stained with $1 \%$ lacmoid in $45 \%$ glacial acetic acid. The maturational stage of each oocyte was determined using phase contrast microscopy (Nikon ${ }^{\circledR}$ Eclipse E200, $\times 1000$ magnification). Oocytes were classified as being in one of the following stages: germinal vesicle $(\mathrm{GV})$, germinal vesicle breakdown (GVBD), metaphase I (MI), anaphase I (AI), telophase I (TI) and metaphase II (MII). Any oocytes that had diffuse or undefined chromatin or had chromosomal aberrations were considered to be abnormal or degenerate.

\section{In vitro maturation (IVM)}

After selection, the COCs were washed and transferred in groups of 25 to 30 to $200 \mu l$ droplets of maturation medium under silicone oil, and then were incubated 
for $24 \mathrm{~h}$ at $39^{\circ} \mathrm{C}$ and $5 \% \mathrm{CO}_{2}$ in air. The maturation medium consisted of TCM-199 supplemented with $10 \% \mathrm{FBS}, 0.01 \mathrm{IU} / \mathrm{ml}$ of FSH, $0.1 \mathrm{mg} / \mathrm{ml}$ of L-glutamine and antibiotic (amikacin at $0.075 \mathrm{mg} / \mathrm{ml}$ ).

\section{In vitro fertilization (IVF) and in vitro culture (IVC)}

Following maturation, COCs were transferred to a $200 \mu \mathrm{l}$ droplet of fertilization medium, which consisted of Tyrode's albumin, lactate and pyruvate (TALP) (Parrish et al., 1995) supplemented with penicillamine (2 $\mathrm{mM})$, hypotaurine $(1 \mathrm{mM})$, epinephrine $(250 \mathrm{mM})$ and heparin $\left(10 \mu \mathrm{g} / \mathrm{ml}^{-1}\right)$. Frozen semen from a Nellore bull, which had previously been tested in our laboratory, was used for IVF. Motile spermatozoa were obtained by the Percoll gradient method $\left(\mathrm{GE}^{\circledR}\right.$ Healthcare, Piscataway, NJ, USA) in microtubes (Machado et al., 2009) and were added to the fertilization droplets containing the COCs at a final concentration of $1 \times 10^{6}$ spermatozoa $\mathrm{ml}^{-1}$. The spermatozoa and oocytes were co-incubated for $18 \mathrm{~h}$ at $39^{\circ} \mathrm{C}$ in $5 \% \mathrm{CO}_{2}$ in air, and the day of in vitro insemination was considered to be D0.

Eighteen hours post-insemination (pi), presumptive zygotes were washed and transferred to $200 \mu$ ldroplets of synthetic oviduct fluid medium (SOFaaci) (Holm et al., 1998) supplemented with $2.77 \mathrm{mM}$ of myoinositol and $5 \% \mathrm{FBS}$, and cultured at $39^{\circ} \mathrm{C}$ in $5 \% \mathrm{CO}_{2}$ in air for 7 days. The embryos were evaluated for cleavage on day $2 \mathrm{pi}$, and the blastocyst rates were determined on days 6 (D6), 7 (D7) and 8 (D8).

\section{Embryo measurements and cell number}

On D7, blastocysts were measured with a Motic Image Plus 2.0 (Moticam ${ }^{\circledR}$, Xiamen, China) and classified by their diameter into three categories: $120-140 \mu \mathrm{m}$, 140-160 $\mu \mathrm{m}$ and $>160 \mu \mathrm{m}$. The embryos $>160 \mu \mathrm{m}$ in diameter were used for cell number evaluation. Embryos were exposed to Hoechst 33342 dye at $1 \mu \mathrm{g} / \mathrm{ml}$ for $5 \mathrm{~min}$ and were subsequently transferred to a slide and covered with a cover slip. The cell nuclei were counted on the slides using an epifluorescence microscope (Zeiss Axiophot, Germany ${ }^{\circledR}$ ) with a wavelength of 330-365 nm excitation/emission $(\times 100$ magnification).

\section{Experimental design}

Experiment 1. Effect of ITS during maturation and culture on embryo production and quality

In this experiment, we evaluated whether the presence of a combination of ITS would affect in vitro embryo production during IVM and IVC. In total, 1549 oocytes obtained from follicles of $3-8 \mathrm{~mm}$ diameter were distributed into four groups. These groups were: (1) the control oocytes; (2) the oocytes supplemented with ITS in the IVM medium for $24 \mathrm{~h}$ (ITS-IVM); (3) the oocytes supplemented with ITS in both the IVM and the IVC medium (ITS-IVM+ITS-IVC); and (4) the oocytes supplemented with ITS in the IVC medium (ITS-IVC). Cleavage rates on D2 and blastocyst rates on D6 and D7 were evaluated. Size and total cell number on D7 were determined.

Experiment 2. Evaluation of the presence of ITS and AA during in vitro maturation to improve the developmental competence of bovine oocytes

In this experiment we investigated if the presence of ITS plus AA in various periods of time during maturation could increase the oocyte's developmental potential moments. In total, 866 oocytes, obtained from 3-8 mm diameter follicles, were distributed into four groups. The groups were: (1) control oocytes, (2) the addition of ITS and AA during IVM in the first $12 \mathrm{~h}$ (ITS+AA- ${ }^{\text {st }} 12 \mathrm{~h} \mathrm{MIV),} \mathrm{(3)} \mathrm{the} \mathrm{addition} \mathrm{of} \mathrm{ITS} \mathrm{and}$ AA during IVM in the last $12 \mathrm{~h}$ (ITS+AA-2 ${ }^{\text {nd }} 12 \mathrm{~h}$ MIV), and (4) the addition of ITS and AA throughout IVM (ITS+AA-24 h MIV). In order to evaluate embryo development, cleavage rate was determined at D2 and blastocyst rates at D6 and D7 after fertilization. On D7, size and total cell number were determined.

Experiment 3. Effect of ITS and AA during in vitro maturation of bovine oocytes on nuclear maturation and embryo development with different levels of competency As we were investigating the potential beneficial effects of ITS and AA during maturation on less competent oocytes, it was necessary to confirm that no difference occurred in the kinetics of maturation between oocytes with lower and higher competence. To this end, we designed an experiment to verify whether the resumption and progression of meiosis occur similarly in oocytes with different degrees of competence. The meiotic stage of oocytes from small, medium and large follicles was evaluated at 0,8 and $24 \mathrm{~h}$ of IVM. The following groups were used: (1) control oocytes aspirated from 3-8 $\mathrm{mm}$ diameter follicles, (2) oocytes obtained from 1-3 mm diameter follicles dissected from the ovary, and (3) oocytes obtained from 6-8 $\mathrm{mm}$ diameter follicles dissected from the ovary. At each time point, the oocytes were denuded, fixed, and stained before being classified according to their meiotic stage. Finally, we evaluated whether supplementation with both ITS and AA during the last $12 \mathrm{~h}$ of IVM increased the quality of oocytes from small follicles by increasing their ability to produce embryos. In total, 376 oocytes were distributed into four groups. These groups were: (1) control aspirated oocytes (Control 3-8 mm), (2) supplemented with ITS and AA in the last $12 \mathrm{~h}$ of IVM of aspirated oocytes (ITS+AA 3-8 mm), (3) control dissected oocytes (Control 1-3 mm), and (4) supplemented with ITS and AA in the last $12 \mathrm{~h}$ of IVM 
Table 1 Effect on embryo development with the inclusion of insulin-transferrin-selenium (ITS) on in vitro maturation (ITS-IVM), in vitro culture (ITS-IVC) or both (ITS-IVM+ITS-IVC)

\begin{tabular}{lcccc}
\hline & & \multicolumn{3}{c}{ Embryo development } \\
\cline { 3 - 5 } Treatments & N oocytes & Cleavage D2 N $(\%)$ & Blastocyst D6 N (\%) & Blastocyst D7 N (\%) \\
\hline Control & 389 & $327(84.0)$ & $129(33.2)$ & $149(38.3)$ \\
ITS-IVM & 392 & $321(81.9)$ & $114(29.1)$ & $130(33.2)$ \\
ITS-IVM+ITS-IVC & 383 & $329(85.9)$ & $112(29.2)$ & $136(35.5)$ \\
ITS-IVC & 385 & $316(82.1)$ & $106(27.5)$ & $135(35.1)$ \\
\hline
\end{tabular}

Data evaluated by chi-square test $(\mathrm{P}<0.05)$.

Table 2 Effect on embryo size with the inclusion of insulin-transferrin-selenium (ITS) in the in vitro maturation medium for $24 \mathrm{~h}$ (ITS-IVM), in the in vitro culture medium (ITS-IVC) or both (ITS-IVM+ITS-IVC) on D7 of culture

\begin{tabular}{lcccc}
\hline & & \multicolumn{3}{c}{ D7 embryo size } \\
\cline { 3 - 5 } Treatment & $N$ embryos & $120-140 \mu \mathrm{m} \mathrm{N}(\%)$ & $140-160 \mu \mathrm{m} \mathrm{N}(\%)$ & $\geq 160 \mu \mathrm{m}(\%) N(\%)$ \\
\hline Control & 149 & $7(4.7)^{a}$ & $29(19.5)^{a}$ & $113(75.8)^{a}$ \\
ITS-IVM & 130 & $1(0.8)^{b}$ & $33(25.4)^{a}$ & $96(73.8)^{a}$ \\
ITS-IVM+ITS-IVC & 136 & $4(2.9)^{a, b}$ & $37(27.2)^{a}$ & $95(69.9)^{a}$ \\
ITS-IVC & 135 & $5(3.7)^{a, b}$ & $34(25.2)^{a}$ & $96(71.1)^{a}$ \\
\hline
\end{tabular}

a, b Different letters indicate significant differences by chi-squared test $(P<0.05)$.

Table 3 Effect on the total cell number of embryos $\geq 160 \mu \mathrm{m}$ with the inclusion of insulin-transferrin-selenium (ITS) in the in vitro maturation medium for $24 \mathrm{~h}$ (ITS-IVM), in the in vitro culture medium (ITS-IVC) or both (ITS-IVM+ITS-IVC) on D7 of culture

\begin{tabular}{lcc}
\hline Treatment & $N$ embryos & Cell number $($ mean \pm SD) \\
\hline Control & 71 & $117.9 \pm 25.5$ \\
ITS-IVM & 64 & $111.3 \pm 20.7$ \\
ITS-IVM+ITS-IVC & 66 & $114.5 \pm 25.6$ \\
ITS-IVC & 56 & $115.6 \pm 23.6$ \\
\hline
\end{tabular}

Data were evaluated by Kruskal-Wallis test $(P<0.05)$.

of dissected oocytes (ITS+AA 1-3 mm). Cleavage rates on D2 and blastocyst rates on D6 and D7, and size and total cell number on D7 were determined.

\section{Statistical analysis}

Data regarding embryonic development, embryo size and kinetics of maturation were analyzed by a chisquared test, and total cell number was analyzed using a Kruskal-Wallis test. Statistical analyses were performed using the Prophet Version 5.0 software (BBN Technologies System, NIH, Bethesda, MD, USA, 1997).

\section{Results}

The addition of ITS during IVM, IVC or the entire culture period did not affect embryonic development, as no differences were observed $(P>0.05)$ in cleavage and blastocyst rates among all of the groups (Table 1 ).
The embryo quality, as assessed by the speed of development and the total cell number, showed no effect due to the presence of ITS. In all of the groups, the majority of the blastocysts had a diameter $\geq 160$ $\mu \mathrm{m}$ at D7, indicating that most of them were of high quality (Table 2). Likewise, when embryos of the same size were compared, the mean number of cells was similar $(P>0.05)$ between all of the groups (Table 3$)$.

When oocytes were exposed to ITS and AA for different periods during IVM, we observed similar cleavage rates $(P>0.05)$ among all of the treatments. However, there was a beneficial effect on blastocyst rate in the presence of ITS and AA when the oocytes were supplemented for the final $12 \mathrm{~h}$ of maturation (Table 4).

Similarly, the data on embryo quality showed a higher percentage of embryos with increased developmental rate for the ITS+AA-2 ${ }^{\text {nd }} 12 \mathrm{~h}$ IVM group when compared with the other treatment groups (Table 5). The percentage of embryos larger 
Table 4 Effect on embryonic development with the inclusion of insulin-transferrin-selenium (ITS) and L-ascorbic acid (AA) during the first $12 \mathrm{~h}$ (ITS+AA- ${ }^{\text {st }} 12 \mathrm{~h}$ IVM), the last $12 \mathrm{~h}$ (ITS+AA-2 ${ }^{\text {nd }} 12 \mathrm{~h} \mathrm{IVM}$ ) and $24 \mathrm{~h}$ (ITS+AA-24 $\mathrm{h} \mathrm{IVM)} \mathrm{of} \mathrm{in} \mathrm{vitro}$ maturation

\begin{tabular}{lcccc}
\hline & & \multicolumn{3}{c}{ Embryonic development } \\
\cline { 3 - 5 } Treatment & $N$ oocytes & Cleavage $N(\%)$ & Blastocyst D6 N (\%) & Blastocyst D7 N (\%) \\
\hline Control & 220 & $182(82.7)^{a}$ & $85(38.6)^{a, b}$ & $87(39.5)^{a}$ \\
ITS+AA-1 st $^{a}$ 2h IVM & 224 & $181(80.8)^{a}$ & $77(34.4)^{a}$ & $90(40.2)^{a}$ \\
ITS+AA-2 $^{a}$ 12h IVM & 213 & $181(85.0)^{a}$ & $93(43.6)^{b}$ & $110(51.6)^{b}$ \\
ITS+AA-24h IVM $^{b}$ & 209 & $167(79.9)^{a}$ & $75(35.9)^{a, b}$ & $86(41.1)^{a}$ \\
\hline
\end{tabular}

${ }^{\mathrm{a}, \mathrm{b}}$ Different letters in the same column indicate significant differences by chi-squared test $(P<0.05)$.

Table 5 Effect on the size of the blastocysts on D7 of culture with the inclusion of insulin-transferrin-selenium (ITS) and $\mathrm{L}$-ascorbic acid (AA) during the first $12 \mathrm{~h}$ (ITS+AA- $1^{\text {st }} 12 \mathrm{~h} \mathrm{IVM}$ ), the last $12 \mathrm{~h}\left(\mathrm{ITS}+\mathrm{AA}-2^{\text {nd }} 12 \mathrm{~h}\right.$ IVM) and $24 \mathrm{~h}$ (ITS+AA-24 h IVM) of in vitro maturation

\begin{tabular}{lcccc}
\hline & & \multicolumn{3}{c}{ D7 embryo size } \\
\cline { 3 - 5 } Treatment & $N$ embryos & $120-140 \mu \mathrm{m} \mathrm{N}(\%)$ & $140-160 \mu \mathrm{m} \mathrm{N}(\%)$ & $\geq 160 \mu \mathrm{m} \mathrm{N}(\%)$ \\
\hline Control & 87 & $0(0)^{a}$ & $22(25.3)^{a, b}$ & $65(74.7)^{a, b}$ \\
ITS+AA-1 ${ }^{\text {st }}$ 12h IVM & 90 & $0(0)^{a}$ & $28(31.1)^{a}$ & $62(68.9)^{a}$ \\
ITS+AA-2 $12 \mathrm{~h}$ IVM & 110 & $0(0)^{a}$ & $18(16.3)^{b}$ & $92(83.7)^{b}$ \\
ITS+AA-24h IVM & 86 & $0(0)^{a}$ & $25(29.0)^{a}$ & $61(71.0)^{a}$ \\
\hline
\end{tabular}

${ }^{a, b}$ Different letters in the same column indicate significant differences by chi-squared test $(P<0.05)$.

Table 6 Effect on cell number in embryos $\geq 160 \mu \mathrm{m}$ on D7 of culture with the inclusion of insulin-transferrin-selenium (ITS) and L-ascorbic acid (AA) during the first $12 \mathrm{~h}$ (ITS+AA- $1^{\text {st }} 12 \mathrm{~h} \mathrm{IVM),} \mathrm{the} \mathrm{last} 12 \mathrm{~h}$ (ITS+AA- ${ }^{\text {nd }} 12 \mathrm{~h} \mathrm{IVM}$ ) and $24 \mathrm{~h}$ (ITS+AA-24 h IVM) of in vitro maturation

\begin{tabular}{lcc}
\hline Treatment & N embryos & Cell number (mean \pm SD) \\
\hline Control & 62 & $131.9 \pm 44.7^{a, b}$ \\
ITS+AA-1 st $12 h$ IVM $_{\text {ITS+AA-2 } 12 h \text { IVM }}$ & 61 & $122.3 \pm 46.1^{a}$ \\
ITS+AA-24h IVM & 74 & $143.2 \pm 49.9^{b}$ \\
ITS & 56 & $124.3 \pm 35.3^{a, b}$ \\
\hline
\end{tabular}

${ }^{\mathrm{a}, \mathrm{b}}$ Different letters indicate different values by Kruskal-Wallis test $(P<0.05)$.

than $160 \mu \mathrm{m}$ in diameter and the total cell number in the larger embryos were similar $(P>0.05)$ between the group exposed to ITS and AA during the last $12 \mathrm{~h}$ of maturation and the control group (Table 6). In contrast, the group exposed to these supplements in the first hour of maturation showed not only a lower rate of blastocyst formation on D7 but also slower development and fewer cells than the group exposed to ITS and AA in the last $12 \mathrm{~h}$ of maturation (Table 6).

Before testing the effect of the presence of ITS and AA on the developmental competence of oocytes from small follicles, we compared the kinetics of nuclear maturation of the small follicle oocytes with those recovered from medium- and large-sized follicles. At $0 \mathrm{~h}$ of maturation the highest percentage $(P<0.05)$ of oocytes in the GV stage was observed from the group obtained from follicles of 6-8 $\mathrm{mm}$ diameter. However, in all of the groups, the percentage of oocytes at the
GV stage was over $90 \%$. We also observed that, at $8 \mathrm{~h}$ of culture, the oocytes from the control group were more advanced in meiosis than the other groups, as most of them had already undergone GVBD, while in the dissected groups approximately $15 \%$ of the oocytes were still at the GV stage (Table 7). However, that difference was not maintained; after $8 \mathrm{~h}$, the nuclear maturation pattern was similar among all of the groups. At $24 \mathrm{~h}$, all of the oocytes, regardless of their group, had completed meiosis (with $90 \%$ at MII stage).

Our assessment of the combinatory effect of ITS and AA during the last $12 \mathrm{~h}$ of IVM on small follicle oocyte developmental capacity showed that the cleavage rate (48 $\mathrm{h}$ pi) and blastocyst production on D6 and D7 of culture were lower compared with those oocytes obtained from follicles larger than $3 \mathrm{~mm}$ (Table 8). No difference was found $(P<0.05)$ in these parameters 
Table 7 Kinetics of nuclear maturation in oocytes recovered by follicular aspiration of 3-8 mm follicles (Control), and oocytes obtained from 1-3 $\mathrm{mm}$ and 6-8 $\mathrm{mm}$ follicles individually dissected from the ovarian cortex

\begin{tabular}{|c|c|c|c|c|c|c|c|c|}
\hline \multirow[b]{2}{*}{ Treatments } & \multirow[b]{2}{*}{$N$ oocytes } & \multicolumn{7}{|c|}{ Stage of meiosis } \\
\hline & & GV $(\%)$ & GVBD (\%) & MI (\%) & $\mathrm{AI}(\%)$ & TI (\%) & MII (\%) & Abnormal (\%) \\
\hline Control $0 \mathrm{~h}$ & 101 & $94(93.06)^{a}$ & $6(5.94)^{a}$ & $1(1.0)^{a}$ & $0(0)^{a}$ & $0(0)^{a}$ & $0(0)^{a}$ & $0(0)^{a}$ \\
\hline $1-3 \mathrm{~mm} 0 \mathrm{~h}$ & 60 & $55(91.66)^{a}$ & $4(6.66)^{a}$ & $1(1.66)^{a}$ & $0(0)^{a}$ & $0(0)^{a}$ & $0(0)^{a}$ & $0(0)^{a}$ \\
\hline $6-8 \mathrm{~mm} 0 \mathrm{~h}$ & 98 & $98(100)^{b}$ & $0(0)^{b}$ & $0(0)^{a}$ & $0(0)^{a}$ & $0(0)^{a}$ & $0(0)^{a}$ & $0(0)^{a}$ \\
\hline Control $8 \mathrm{~h}$ & 103 & $3(2.91)^{a}$ & $48(46.60)^{a}$ & $52(50.48)^{a}$ & $0(0)^{a}$ & $0(0)^{a}$ & $0(0)^{a}$ & $0(0)^{a}$ \\
\hline $1-3 \mathrm{~mm} 8 \mathrm{~h}$ & 63 & $9(14.28)^{b}$ & $41(65.07)^{b}$ & $13(20.63)^{b}$ & $0(0)^{a}$ & $0(0)^{a}$ & $0(0)^{a}$ & $0(0)^{a}$ \\
\hline $6-8 \mathrm{~mm} 8 \mathrm{~h}$ & 89 & $15(16.85)^{b}$ & $64(71.91)^{b}$ & $10(11.23)^{b}$ & $0(0)^{a}$ & $0(0)^{a}$ & $0(0)^{a}$ & $0(0)^{a}$ \\
\hline Control $24 \mathrm{~h}$ & 70 & $0(0)^{a}$ & $1(1.42)^{a}$ & $0(0)^{a}$ & $1(1.42)^{a}$ & $1(1.42)^{a}$ & $64(91.42)^{a}$ & $3(4.28)^{a, b}$ \\
\hline $1-3 \mathrm{~mm} 24 \mathrm{~h}$ & 75 & $0(0)^{a}$ & $1(1.33)^{a}$ & $0(0)^{a}$ & $2(2.66)^{a}$ & $0(0)^{a}$ & $67(89.33)^{a}$ & $5(6.66)^{b}$ \\
\hline $6-8 \mathrm{~mm} 24 \mathrm{~h}$ & 67 & $0(0)^{a}$ & $0(0)^{a}$ & $0(0)^{a}$ & $3(4.47)^{a}$ & $3(4.47)^{a}$ & $61(91.04)^{a}$ & $0(0)^{a}$ \\
\hline
\end{tabular}

${ }^{\mathrm{a}, \mathrm{b}}$ Different letters indicate different values by chi-squared test $(P<0.05)$. GV: germinal vesicle; GVBD: germinal vesicle breakdown; MI: metaphase I; AI: anaphase I; TI: telophase I; MII: metaphase II.

Table 8 Effect on embryonic development with the inclusion of insulin-transferrin-selenium (ITS) and L-ascorbic acid (AA) during the last $12 \mathrm{~h}$ of in vitro maturation (IVM) on oocytes aspirated from 3-8 mm follicles (ITS+AA 3-8 mm) and oocytes from 1-3 mm follicles (ITS+AA 1-3 mm) dissected from ovarian cortex

\begin{tabular}{lcccc}
\hline & & \multicolumn{3}{c}{ Embryonic development } \\
\cline { 3 - 5 } Treatment & N oocytes & Cleavage D2 (\%) & Blastocyst D6 (\%) & Blastocyst D7 (\%) \\
\hline Control 3-8 mm & 143 & $128(89.5)^{a}$ & $52(36.4)^{a}$ & $70(49.0)^{a}$ \\
ITS+AA 3-8 mm & 141 & $130(92.2)^{a}$ & $57(40.4)^{a}$ & $86(61.0)^{b}$ \\
Control 1-3 mm & 45 & $22(49.9)^{b}$ & $1(2.2)^{b}$ & $2(4.4)^{c}$ \\
ITS+AA 1-3 mm & 47 & $24(51.0)^{b}$ & $6(12.8)^{b}$ & $7(14.9)^{c}$ \\
\hline
\end{tabular}

a,b,c Different letters indicate different values by chi-squared test $(P<0.05)$.

between the groups of oocytes from small follicles. However, as in Experiment 2, a beneficial effect on the blastocyst formation rate was observed in the control group after the addition of ITS and AA during the last $12 \mathrm{~h}$ of IVM (Table 8).

The embryo quality results are presented in Tables 8 and 9. The ITS+AA 3-8 $\mathrm{mm}$ group had similar results to those obtained in Experiment 2. The oocytes obtained from small follicles resulted in no embryos or a low number of embryos in both groups, which makes it impossible to compare the low competence group to the control. The percentage of blastocysts with a size $>160 \mu \mathrm{m}$ and the total cell numbers were similar between ITS+AA $1-3 \mathrm{~mm}$ and Control 3-8 mm (Table 9).

\section{Discussion}

In the present study we investigated whether the addition of ITS and AA during maturation and embryo culture would improve the yield and quality of IVP embryos by analyzing blastocyst development, size and cell numbers.
Initially, ITS addition during IVM, IVC or during the entire culture period was assessed for an effect on embryo development. The data show that the presence of ITS at any stage of IVP did not affect the quantity or the quality of embryos produced. Our results differ from those previously reported for porcine oocytes (Jeong et al., 2008).

The differences in the results of these studies may be due to the maturation time for porcine oocytes, which is twice as long as that of bovine oocytes (Hyttel et al., 2000). The longer time required for maturation may lead to a greater accumulation of free radicals and other harmful substances in the medium, making the action of the ITS more evident.

Another factor that may be responsible for the differences observed between the studies is the protein source used in the IVM medium. Our medium was supplemented with FBS, which contains hormones, growth factors, vitamins, heavy metal chelators, peptides, proteins, fatty acids, carbohydrates and other components (Keskintepe \& Brackett, 1996). In contrast, the comparative study used PVA, which is a well defined macromolecule. Therefore, it is quite possible that some substances present in FBS could mimic the 
Table 9 Effect on the size of embryos and total cell number in D7 culture with the inclusion of insulin-transferrin-selenium (ITS) and L-ascorbic acid (AA) during the first $12 \mathrm{~h}$ of in vitro maturation (IVM) on oocytes aspirated from 3-8 mm follicles (ITS+AA 3-8 mm), and oocytes from 1-3 mm follicles (ITS+AA 1-3 mm) dissected from the ovary

\begin{tabular}{|c|c|c|c|c|c|}
\hline \multirow[b]{2}{*}{ Treatment } & \multirow[b]{2}{*}{$N$ embryos } & \multicolumn{4}{|c|}{ Blastocyst on D7 - embryo size and total cell number of embryos $\geq 160 \mu \mathrm{m}$} \\
\hline & & $120-140 \mu \mathrm{m}(\%)$ & $140-160 \mu \mathrm{m}(\%)$ & $\geq 160(\%)$ & Total cell number $\geq 160 \mu \mathrm{m}$ \\
\hline Control 3-8mm & 70 & $0(0)^{a}$ & $20(28.6)^{a}$ & $50(71.4)^{a}$ & $133.8 \pm 47.2^{a}$ \\
\hline ITS+AA 3-8mm & 86 & $0(0)^{a}$ & $8(9.3)^{b}$ & $78(90.7)^{b}$ & $172.8 \pm 60.1^{b}$ \\
\hline Control 1-3mm & 2 & $0(0)^{a}$ & $2(100)^{c}$ & $0(0)^{c}$ & 0 \\
\hline $\mathrm{ITS}+\mathrm{AA} 1-3 \mathrm{~mm}$ & 7 & $0(0)^{a}$ & $3(42.9)^{a}$ & $4(57.1)^{a}$ & $107.75 \pm 60.6^{a, b}$ \\
\hline
\end{tabular}

a,b,c Different letters indicate different values by Kruskal-Wallis test $(P<0.05)$.

action of ITS (Keskintepe \& Brackett, 1996), masking its effects.

Some studies have reported that combining ITS during oocyte maturation with AA, which is the most important water-soluble antioxidant present in the ovaries, has a beneficial effect on oocyte developmental capacity (Tatemoto et al., 2004; Tao et al., 2010). Although transferrin and selenium, present in the ITS combination, also have antioxidant activities, we hypothesized that their effect during culture was masked by the presence of FBS. To test the previously reported potential beneficial effect of antioxidants on the oocytes, we added AA to the maturation medium in Experiment 2, along with ITS. Considering that Córdova et al. (2010) and other authors (Blondin et al., 1997; Tao et al., 2004; Tatemoto et al., 2004; Dalvit et al., 2005; Kere et al., 2013) found that the addition of AA alone to the oocyte maturation medium exerted no effect on bovine and porcine COCs, we only evaluated the combination of both compounds. To assess if the effects of adding ITS and AA occur throughout maturation or if they are restricted to a certain period only, we supplemented the medium at different intervals during IVM.

The results showed a beneficial effect on blastocyst rate when oocytes were exposed to ITS and AA in the final $12 \mathrm{~h}$ of IVM. However, embryo quality, as assessed by the size and number of cells on D7, was similar to that of the control group. The effects of those individual components (ITS and AA) supplemented in maturation medium in different species have been reported by several authors (Bu et al., 2004; Dalvit et al., 2005; Jeong et al., 2008; Rossetto et al., 2009; Tao et al., 2010; Hu et al., 2011; Kere et al., 2013). However, studies using ITS and AA in combination, as in the present study, are scarce.

In the present study, the best embryonic development results were found in the group exposed to ITS and AA in the second part of maturation. It is possible that a higher concentration of free radicals and other substances harmful to the oocyte could be present in the last hours of IVM compared with the early hours.
Thus, the accumulation of injurious substances during the first $12 \mathrm{~h}$ of IVM could be offset by adding ITS and AA during the last $12 \mathrm{~h}$ of IVM to reduce stress on the oocytes. This effect would be responsible for the better results obtained in this group.

Based upon reports in the literature, which show that ITS and AA supplementation during maturation improved the developmental competence of oocytes obtained from pre-pubertal females, we questioned whether changing the maturation conditions would improve the IVP outcome of less competent oocytes obtained from small follicles.

To evaluate this possibility, we used the follicle size model, which is a well described model to obtain oocytes of varying competencies (Caixeta et al., 2009; Racedo et al., 2009; Bessa et al., 2013). We then tested the effect of exposing less competent oocytes to ITS and AA during the last $12 \mathrm{~h}$ of maturation.

Because we were unsure whether the kinetics of meiosis were similar in oocytes obtained from different competencies, we first confirmed these kinetics. The results showed that, at $0 \mathrm{~h}$ of maturation, there was a higher percentage of oocytes from follicles of 6$8 \mathrm{~mm}$ in GV compared with the other groups. Despite the significant difference, this has little biological significance, because all of the groups showed more than $90 \%$ of the oocytes at the GV stage, which is consistent with other findings in the literature (Dode et al., 2000; Dode \& Adona, 2001). At $8 \mathrm{~h}$ of maturation, the control group was more advanced in meiosis than the other groups. However, the groups of oocytes obtained from dissected follicles that had different degrees of competence were at the same stage at $8 \mathrm{~h}$ and $24 \mathrm{~h}$ of maturation. Finally, we evaluated the effect on less competent oocytes of adding both ITS and AA during the last $12 \mathrm{~h}$ of IVM. The results for the control group confirmed the beneficial effect of ITS and AA on cytoplasmatic maturation and on subsequent blastocyst development and quality, as was observed in the earlier experiments. When oocytes from 1-3 mm diameter follicles were used in the present study, no beneficial effect of adding ITS and AA was observed. 
Our results conflict with those found in the literature, where it is reported that ITS plus AA used in less competent oocytes had improved the development potential of the oocyte (Córdova et al., 2010; Hammami et al., 2013). However, those studies used oocytes from pre-pubertal goats as their experimental model. Although most oocytes at this stage of development have lower competence and are obtained from various follicle sizes, it is possible that some oocytes had already reached competence (Revel et al., 1995; Alberio \& Palma, 1998). In contrast, the experimental model used to classify oocyte competence in our study ensures the similarity of the biological material, because the oocytes were obtained from follicles of defined sizes dissected from the ovarian cortex (Caixeta et al., 2009; Bessa et al., 2013). This difference in experimental design could increase the lowered competency of the oocytes that we used, which could account for the differences in blastocyst rates (Córdova et al., 2010; Hammami et al., 2013). In addition, oocyte competence is directly related to the transcript and protein accumulation in the oocyte before resuming meiosis and completing maturation (Dode et al., 2006; Caixeta et al., 2009; Racedo et al., 2009; Bessa et al., 2013). Therefore, the action of substances such as ITS and AA, which act mainly on the production of free radicals and undesirable products in the oocyte and maturation medium at levels other than the molecular (Tilly \& Tilly, 1995; Eppig et al., 2000; Murray et al., 2001; Kim et al., 2005; Lee et al., 2005), may not have been sufficient to improve competence. Unless the oocytes could be exposed to those substances while they are kept arrested at the GV stage, an effect at the molecular level would not be possible. In fact, we are not dismissing the importance of those substances for the oocytes and for the environment where oocytes are exposed. The beneficial effects of these agents could help to explain the improvement observed in the embryonic development of oocytes treated with ITS and AA during IVM.

Despite the small sample sizes and lack of differences among groups $1-3$, when ITS and AA were added, the outcome seems to have improved. This reinforces the hypothesis that the supplements do not improve embryo competence but affect the oocyte culture environment. It is possible that antioxidant substances may protect against oxidative stress in the cumulus cells, which are known to have an important role in supporting oocyte maturation.

Based on our findings, we can conclude that the addition of the insulin-transferrin-selenium complex plus ascorbic acid improved ability of oocytes to develop to blastocyst stage when used during the last $12 \mathrm{~h}$ of IVM. Furthermore, no such effect was observed when less competent oocytes were exposed to the same conditions.

\section{Acknowledgements}

This research was supported by Embrapa MP1 (grant number - 003.0709040000). The authors thank the personnel at QualiMax Meat Packing (Luziânia, Goiás, Brazil) for their generosity in supplying ovaries for research.

\section{Conflicts of interests}

None of the authors has any conflict of interest to declare.

\section{References}

Agarwal, A., Durairajanayagam, D. \& du Plessis, S.S. (2014). Utility of antioxidants during assisted reproductive techniques: an evidence based review. Reprod. Biol. Endocrinol. 12, 112.

Alberio, R. \& Palma, G. (1998). Development of bovine oocytes matured in a defined medium supplemented with a low concentration of rhFSH. Theriogenology 49, 195.

Augustin, R., Pocar, P., Wrenzycki, C., Niemann, H. \& Fischer, B. (2003). Mitogenic and anti-apoptotic activity of insulin on bovine embryos produced in vitro. Reproduction 126, 91-9.

Bessa, I.R., Nishimura, R.C., Franco, M.M. \& Dode, M.A. (2013). Transcription profile of candidate genes for the acquisition of competence during oocyte growth in cattle. Reprod. Domest. Anim. 48, 781-9.

Blondin, P., Guilbault, L.A. \& Sirard, M.A. (1997). The time interval between FSH-P administration and slaughter can influence the developmental competence of beef heifer oocytes. Theriogenology 48, 803-13.

Bu, S., Xie, H., Tao, Y., Wang, J. \& Xia, G. (2004). Nitric oxide influences the maturation of cumulus cell-enclosed mouse oocytes cultured in spontaneous maturation medium and hypoxanthine-supplemented medium through different signaling pathways. Mol. Cell. Endocrinol. 223, 85-93.

Caixeta, E., Ripamonte, P., Franco, M., Junior, J. \& Dode, M. (2009). Effect of follicle size on mRNA expression in cumulus cells and oocytes of Bos indicus: an approach to identify marker genes for developmental competence. Reprod. Fertil. Dev. 21, 655-64.

Cerri, R.L., Rutigliano, H.M., Lima, F.S., Araujo, D.B. \& Santos, J.E. (2009). Effect of source of supplemental selenium on uterine health and embryo quality in highproducing dairy cows. Theriogenology 71, 1127-37.

Chwa, M., Atilano, S.R., Reddy, V., Jordan, N., Kim, D.W. \& Kenney, M.C. (2006). Increased stress-induced generation of reactive oxygen species and apoptosis in human keratoconus fibroblasts. Invest. Ophthalmol. Vis. Sci. 47, 1902-10.

Córdova, B., Morató, R., Izquierdo, D., Paramio, T. \& Mogas, T. (2010). Effect of the addition of insulintransferrin-selenium and/or L-ascorbic acid to the in vitro 
maturation of prepubertal bovine oocytes on cytoplasmic maturation and embryo development. Theriogenology 74, 1341-8.

Dalvit, G., Llanes, S.P., Descalzo, A., Insani, M., Beconi, M. \& Cetica, P. (2005). Effect of alpha-tocopherol and ascorbic acid on bovine oocyte in vitro maturation. Reprod. Domest. Anim. 40, 93-7.

Dode, M.A., Dufort, I., Massicotte, L. \& Sirard, M.A. (2006). Quantitative expression of candidate genes for developmental competence in bovine two-cell embryos. Mol. Reprod. Dev. 73, 288-97.

Dode, M.A.N. \& Adona, P.R. (2001). Developmental capacity of Bos indicus oocytes after inhibition of meiotic resumption by 6-dimethylaminopurine. Anim. Reprod. Sci., 65, 171-80.

Dode, M.A.N., Rodovalho, N.C., Ueno, V.G. \& de Oliveira Alves, R.G. (2000). Efeito do tamanho do folículo na maturação nuclear e citoplasmática de ovócitos de fêmeas zebuínas. [Effect of follicle size in nuclear and cytoplasmic maturation of oocytes from zebu cows] Pesquisa Agropecuária Brasileira 35, 207-14.

Eppig, J.J., Hosoe, M., O'Brien, M.J., Pendola, F.M., Requena, A. \& Watanabe, S. (2000). Conditions that affect acquisition of developmental competence by mouse oocytes in vitro: $\mathrm{FSH}$, insulin, glucose and ascorbic acid. Mol. Cell. Endocrinol. 163, 109-16.

George, F., Daniaux, C., Genicot, G., Verhaeghe, B., Lambert, P. \& Donnay, I. (2008). Set up of a serum-free culture system for bovine embryos: embryo development and quality before and after transient transfer. Theriogenology 69, 612-23.

Hammami, S., Morató, R., Romaguera, R., Roura, M., Catalá, M.G., Paramio, M.T., Mogas, T. \& Izquierdo, D. (2013). Developmental competence and embryo quality of small oocytes from pre-pubertal goats cultured in IVM medium supplemented with low level of hormones, insulin-transferrin-selenium and ascorbic acid. Reprod. Dom. Anim. 48, 339-44.

Holm, P., Shukri, N.N., Vajta, G., Booth, P., Bendixen, C. \& Callesen, H. (1998). Developmental kinetics of the first cell cycles of bovine in vitro produced embryos in relation to their in vitro viability and sex. Theriogenology $\mathbf{5 0}$, 1285-99.

Hu, J., Ma, X., Bao, J.C., Li, W., Cheng, D., Gao, Z., Lei, A., Yang, C. \& Wang, H. (2011). Insulin-transferrin-selenium (ITS) improves maturation of porcine oocytes in vitro. Zygote 19, 191-7.

Hyttel, P., Viuff, D., Laurincik, J., Schmidt, M., Thomsen, P.D., Avery, B., Callesen, H., Rath, D., Niemann, H., Rosenkranz, H., Schellander, K., Ochs, R.L. \& Greve, T. (2000). Risks of in-vitro production of cattle and swine embryos: aberrations in chromosome numbers, ribosomal RNA gene activation and perinatal physiology. Hum. Reprod. 15, 87-97.

Jeong, Y.W., Hossein, M.S., Bhandari, D.P., Kim, Y.W., Kim, J.H., Park, S.W., Lee, E., Park, S.M., Jeong, Y.I., Lee, J.Y., Kim, S. \& Hwang, W.S. (2008). Effects of insulin-transferrin-selenium in defined and porcine follicular fluid supplemented IVM media on porcine IVF and SCNT embryo production. Anim. Reprod. Sci. 106, $13-24$.
Kere, M., Siriboon, C., Lo, N.-W., Nguyen, N.T. \& Ju, J.-C. (2013). Ascorbic acid improves the developmental competence of porcine oocytes after parthenogenetic activation and somatic cell nuclear transplantation. J. Reprod. Dev. 59, 78-84.

Keskintepe, L. \& Brackett, B.G. (1996). In vitro developmental competence of in vitro-matured bovine oocytes fertilized and cultured in completely defined media. Biol. Reprod. 55, 333-9.

Kim, S., Lee, G.S., Lee, S.H., Kim, H.S., Jeong, Y.W., Kim, J.H., Kang, S.K., Lee, B.C. \& Hwang, W.S. (2005). Embryotropic effect of insulin-like growth factor (IGF)-I and its receptor on development of porcine preimplantation embryos produced by in vitro fertilization and somatic cell nuclear transfer. Mol. Reprod. Dev. 72, 88-97.

Lee, M.S., Kang, S.K., Lee, B.C. \& Hwang, W.S. (2005). The beneficial effects of insulin and metformin on in vitro developmental potential of porcine oocytes and embryos. Biol. Reprod. 73, 1264-8.

Machado, G.M., Carvalho, J.O., Filho, E.S., Caixeta, E.S., Franco, M.M., Rumpf, R. \& Dode, M.A. (2009). Effect of Percoll volume, duration and force of centrifugation, on in vitro production and sex ratio of bovine embryos. Theriogenology 71, 1289-97.

Murray, A., Molinek, M., Baker, S., Kojima, F., Smith, M., Hillier, S. \& Spears, N. (2001). Role of ascorbic acid in promoting follicle integrity and survival in intact mouse ovarian follicles in vitro. Reproduction 121, 89-96.

Parrish, J.J., Krogenaes, A. \& Susko-Parrish, J.L. (1995). Effect of bovine sperm separation by either swim-up or Percoll method on success of in vitro fertilization and early embryonic development. Theriogenology 44, 859-69.

Racedo, S.E., Wrenzycki, C., Lepikhov, K., Salamone, D., Walter, J. \& Niemann, H. (2009). Epigenetic modifications and related mRNA expression during bovine oocyte in vitro maturation. Reprod. Fertil. Dev. 21, 738-48.

Revel, F., Mermillod, P., Peynot, N., Renard, J.P. \& Heyman, Y. (1995). Low developmental capacity of in vitro matured and fertilized oocytes from calves compared with that of cows. J. Reprod. Fertil. 103, 115-20.

Rossetto, R., Lima-Verde, I.B., Matos, M.H., Saraiva, M.V., Martins, F.S., Faustino, L.R., Araujo, V.R., Silva, C.M., Name, K.P., Sn, S.N., Campello, C.C., Figueiredo, J.R. \& Blume, H. (2009). Interaction between ascorbic acid and follicle-stimulating hormone maintains follicular viability after long-term in vitro culture of caprine preantral follicles. Domest. Anim. Endocrinol. 37, 112-23.

Tao, Y., Chen, H., Tian, N.N., Huo, D.T., Li, G., Zhang, Y.H., Liu, Y., Fang, F.G., Ding, J.P. \& Zhang, X.R. (2010). Effects of L-ascorbic acid, $\alpha$-tocopherol and co-culture on in vitro developmental potential of porcine cumulus cells free oocytes. Reprod. Domest. Anim. 45, 19-25.

Tao, Y., Zhou, B., Xia, G., Wang, F., Wu, Z. \& Fu, M. (2004). Exposure to L-ascorbic acid or $\alpha$-tocopherol facilitates the development of porcine denuded oocytes from metaphase I to metaphase II and prevents cumulus cells from fragmentation. Reprod. Domest. Anim. 39, 52-7.

Tatemoto, H., Muto, N., Sunagawa, I., Shinjo, A. \& Nakada, T. (2004). Protection of porcine oocytes against cell damage caused by oxidative stress during in vitro maturation: role 
of superoxide dismutase activity in porcine follicular fluid. Biol. Reprod. 71, 1150-7.

Tilly, J.L. \& Tilly, K.I. (1995). Inhibitors of oxidative stress mimic the ability of follicle-stimulating hormone to suppress apoptosis in cultured rat ovarian follicles. Endocrinology 136, 242-52.
Wydooghe, E., Heras, S., Dewulf, J., Piepers, S., Van den Abbeel, E., De Sutter, P., Vandaele, L. \& Van Soom, A. (2014). Replacing serum in culture medium with albumin and insulin, transferrin and selenium is the key to successful bovine embryo development in individual culture. Reprod. Fertil. Dev. 26, 717-24. 